\title{
Correction to: Effect of different activations of silver nanoparticle irrigants on the elimination of Enterococcus faecalis
}

\author{
Farzaneh Afkhami ${ }^{1} \cdot$ Paniz Ahmadi $^{2} \cdot$ Nasim Chiniforush ${ }^{2} \cdot$ Aidin Sooratgar $^{1}(\mathbb{C}$
}

Published online: 5 January 2022

(c) Springer-Verlag GmbH Germany, part of Springer Nature 2021

\section{Correction to: Clinical Oral Investigations}

https://doi.org/10.1007/s00784-021-03979-5

The original version of the article "Effect of different activations of silver nanoparticle irrigants on the elimination of Enterococcus faecalis" contained an error in the spelling of the last name of the first author Afkhami, which was incorrectly given as Afhkami.

The original article has been corrected.

Publisher's note Springer Nature remains neutral with regard to jurisdictional claims in published maps and institutional affiliations.

The original article can be found online at https://doi.org/10.1007/ s00784-021-03979-5.

\section{Aidin Sooratgar}

A-sooratgar@sina.tums.ac.ir

1 Department of Endodontics, School of Dentistry, Tehran University of Medical Sciences, End of North Kargar Street, 1439955991 Tehran, Iran

2 Laser Research Center of Dentistry, Dentistry Research Institute, Tehran University of Medical Science, 1441987566 Tehran, Iran 